\title{
PERSEPSI CIVITAS AKADEMIK PADA KENYAMANAN TATA RUANG KAMPUS UINSU MEDAN (Pendekatan Sosiologi Agama dan Transdisiplin Keilmuan)
}

\author{
Muhammad Zailani \\ Universitas Islam Negeri Sumatera Utara (UINSU) Medan \\ mubammadrailani@uinsu.ac.id
}

\begin{abstract}
Abstrak
Penelitian ini berawal dari asumsi dasar bahwa kampus sebagai tempat pendidikan tinggi dalam menghasilkan generasi penerus agama dan profesional tentu memerlukan situasi yang nyaman bagi orang-orang akademis sesuai dengan Visi UIN SU yang terus mengembangkan infrastruktur kampus belakangan ini. Untuk alasan ini, penting untuk melihat pandangan komunitas akademik UIN SU tentang kenyamanan konsep ruang UIN SU berdasarkan pengetahuan, pengalaman, sebagai Muslim dan pemilik budaya lokal. di Sumatera Utara. Penelitian ini menggunakan pendekatan kuantitatif deskriptif menggunakan skala likert dalam mengukur skala persepsi subjek penelitian. Subjek penelitian terdiri dari pejabat struktural di kampus UIN SU, dosen biasa, karyawan, dan mahasiswa. Hasil penelitian menunjukkan bahwa sivitas akademika UIN SU umumnya memiliki persepsi positif terhadap perencanaan tata ruang dan tata ruang bangunan di kampus UIN SU Medan, yang mencapai rata-rata 62,25\%. Namun, 60,6\% dari komunitas akademik masih menyatakan bahwa infrastruktur UIN SU belum dapat diakses oleh para penyandang cacat, 43,7\% mengatakan bahwa sirkulasi di dalam dan ke luar kampus tidak lancar dan 40,8\% mengatakan bahwa ruang terbuka hijau tidak cukup. Temuan ini menunjukkan bahwa komunitas akademik memiliki persepsi moderat atau netral terhadap sirkulasi di luar kampus, kenyamanan, kebersihan dan aroma, dan kenyamanan iklim. Di sisi lain, pembangunan infrastruktur kampus sebelumnya tidak memperhatikan hubungan sosial, dan bangunan dalam konteks Islam dan budaya lokal. Kemudian beberapa infrastruktur atau fasilitas pendukung dibangun sehubungan dengan hubungan sosial siswa, serta struktur bangunan Islam. Untuk alasan ini, penting untuk melihat kebijakan berdasarkan kebutuhan ruang terbuka hijau, keramahan infrastruktur untuk penyandang cacat dan sistem sirkulasi masuk dan keluar kampus yang tidak membingungkan. Juga penting untuk merumuskan kebijakan pembangunan infrastruktur yang menyediakan ruang yang nyaman untuk ibadah Muslim dengan sentuhan budaya lokal.
\end{abstract}

Kata kunci: Kenyamanan, Persepsi, Ruang kampus, Relasi Sosial, Sosiologi Agama

Abstract

This research starts from the rationale assumption of the campus as a place of higher education to produce the next generation of religions and professionals, of course, requires support for academic people in accordance with the Vision of UIN SU, which continues to develop the infrastructure of this developed campus. For this reason, it is important to see the views of the UIN SU academic community about the convenience of the UIN SU space concept based on knowledge, experience, as Muslims and owners of local culture. in North Sumatra. This research uses descriptive quantitative by using Likert scale in measuring the perception scale of research 
subjects. The research subjects consisted of structural officials at UIN SU campus, ordinary lecturers, employees, and students. The results showed that the general academics of UIN SU had a positive perception of spatial planning and building layout on the UIN SU Medan campus, which reached an average of $62.25 \%$. However, $60.6 \%$ of the academic community still stated that UIN SU infrastructure was not accessible to people with disabilities, $43.7 \%$ said that circulation on and off campus was inefficient and $40.8 \%$ said that green open space was not enough. These findings indicate that the academic community has a moderate or neutral perception of off-campus circulation, comfort, cleanliness and aroma, and comfort comfort. On the other hand, campus infrastructure development previously did not pay attention to social relations, and buildings in Islamic relations and local culture. Then some supporting infrastructure or facilities are built with students' social relations, and Islamic building structures. For this reason, it is important to look. at policies on the need for green open space, infrastructure protection for people with disabilities and unauthorized entrance and exit systems of campus circulation. It is also important to formulate an infrastructure development policy that provides a comfortable space for Muslim worship with a touch of local culture.

Keywords: Campus Spatial, Perception, Comfortable, Sociology of Religion, Social Relation

\section{Pendahuluan}

Universitas Islam Negeri Sumatera Utara Medan ( UIN SU Medan ) sebagai salah satu perguruan tinggi Islam perlu mengembangkan cara berpikir akademis; philosofis - logis - theologis itu dalam suasana kampus yang mendukung. Ini sebagian besar dipengaruhi oleh faktor kenyamanan bekerja di kampus dimana sebagian besar waktu dihabiskan oleh insan akademis. Untuk itu penting civitas akademis UIN SU Medan memiliki kenyamanan tata ruang agar segala sesuatu yang berproses di dalamnya dapat merasakan kenyamanan tersebut.

Sebuah bangunan dalam kampus juga harus memenuhi aspek standar pelayanan, keamanan, keselamatan, kenyamanan dan kesehatan kerja civitas akademis sehingga dapat berfungsi secara optimal. Salah satu aspek yang paling berpengaruh langsung terhadap civitas akademis adalah adalah aspek kenyamanan. Kenyamanan dibagi menjadi dua jenis, yaitu kenyamanan fisik dan psikis. Kenyamanan psikis bersifat personal, dan kualitatif. Kenyamanan psikis termasuk bagaimana tata ruang kampus memberikan ruang dan kesempatan antar civitas akademik dapat berinteraksi dalam zona nyaman tetap dalam tatanan Islam, sehingga di kampus dirasakan seperti di rumah sendiri. Sementara kenyamanan fisik di ukur dari kenyamanan ruang, sirkulasi, pencahayaan yang juga berpengaruh pada kenyamanan psikis.

Pendekatan transdisiplin terus dikembang di UINSU untuk mencapai UIN SU Juara dan world class university. Pendekatan berbasis masalah, partisipatif, penggunaan praktik antar disiplin ilmu dan dikembangkan menjadi resolusi antar disiplin coba diterapkan oleh civitas akademik. Hal ini tidak terkecuali dalam pengembangan kenyamanan tata ruang kampus. Untuk itu perlu pandangan partisipatif insan akademik UIN SU terhadap kenyamanan tata ruang kampus seperti yang meliputi 
kenyamanan sirkulasi, kenyamanan iklim atau kekuatan alam, kenyamanan aroma atau bau-bauan, kenyamanan kebisingan, kenyamanan bentuk, kenyamanan keamanan, kenyamanan kebersihan, dan kenyamanan keindahan.

Pendekatan partisipatif ini merupakan salah satu syarat dari penggunaan pendekatan transdisiplin ilmu. Untuk itulah dilakukan penelitian analitik deskriptif ini untuk mendapat pandangan dari civitas akademik pada kenyamanan dalam perspektif phisik dan sosiologis yang berlandaskan Islam pada tata ruang kampus di UIN SU Medan, khususnya di kampus II jalan Willem Iskandar.

Ada dua rumusan masalah yang kemudian dimunculkan untuk menjawab persepsi civitas akademik pada kenyamanan tata ruang kampus di UIN SU. Rumusan masalah pertama adalah Bagaimana persepsi civitas akademis UIN SU Medan terhadap kenyamanan tata ruang kampus UIN SU Medan? Dan rumusan masalah yang kedua adalah apa faktor-faktor yang menyebabkan pembentukan persepsi civitas akademik terhadap kenyamanan tata ruang kampus UIN SU Medan? Agar analisa masalahnya terfokus maka analisa persepsi ini khusus pada ruang lingkup pengalaman dan pengetahuan sosial agama responden yang mempengaruhi pandangan pada kenyamanan tata ruang kampus dengan objek kampus UIN SU Medan yang beralamat di jalan Williem Iskandar, Medan Estate.

Responden study ini adalah struktur pimpinan universitas, dosen, staf/pegawai, dan mahasiswa di lingkungan kampus UIN SU yang terdiri dari rektorat, Lembaga Penelitian dan Pengabdian Masyarakat (LP2M), dan enam fakultas; Fakultas Ushuluddin dan Studi Islam (FUSI), Fakultas Ilmu Sosial (FIS), Fakultas Ilmu Tarbiyah dan Keguruan (FITK), Fakultas Dakwah dan Komunikasi (FDK), Fakultas Hukum Syariah (FHS) dan Fakultas Ekonomi dan Bisnis Islam (FEBI).

Teori dasar dalam Islam yang dipergunakan adalah QS. Al-Furqan:48 - 49, Al-A'raf ayat 56, An-Nahl ayat 80. Menurut Dyayadi (2008) Konsep perencanaan Tata ruang didalam Islam sudah lama terkonsep dengan baik terbukti bahwa adanya bangunan bernuansa Islam misalnya di Iskandariah, Madinah, Andalusia ( Spanyol), Basrah, Kufah, Baitul Maqdis, Baitul Laham (Bethelem), Darussalam (Yerussalem), artinya hasil karya Islam tersebut telah menjadi sejarah dunia.

Sehingga sebagai generasi penerus senantiasa untuk tetap berpegang teguh kepada ajaran Islam tentunya dalam kontek penataan ruang. Kharakteristik tata ruang menggunakan pendekatan Lynch, 1960, Schultz, 1980 dan Tracik 1986 bahwa pola tata ruang dipahami sebagai pola perwujudan struktur ruang dan pola ruang yang terjadi. Sehingga karakter dan pola tata ruang dapat 
diartikan sebagai perwujudan struktur dan pola peruntukan ruang baik untuk fungsi lindung dan budi daya yang membentuk citra dan identitas sebuah kawasan.

Untuk mengukur pandangan responden maka dipergunakan teori persepsi Kotler (2000) bahwa persepsi sebagai proses bagaimana seseorang menyeleksi mengatur dan menginterprestasikan masukan-masukan informasi untuk menciptakan gambaran keseluruhan yang berarti” dan Robbins (2003) "mendeskripsikan persepsi dalam kaitannya dengan lingkungan, yaitu sebagai proses dimana individu-individu mengorganisasikan dan menafsirkan kesan indera mereka kepada lingkungan mereka". Dengan demikian persepsi dapat disimpulkan sebagai pandangan seseorang terhadap suatu objek yang dipengaruhi penginderaannya, pengalamannya, dan kebiasaannya sehingga dapat memberi makna.

Pendekatan trans-disiplin dalam pengelolaan Tata ruang menggunakan teori Chermayeff \& Alexander tenang bagaimana tata ruang didisain mulai untuk urusan privat hingga urusan public; Individual-private, family private, group-private, group public, urban-semi public. Menurutnya mereka tata ruang suatu kota atau rumah akan merefleksikan bagaimana pengambil kebijakan, penghuni kota dan penghuni rumah mengkonsepsi dan mengejewantahkan ruang privacy dan ruang publik.

Berdasarkan dasar dari teori-teori diatas maka kemudian pengertian persepsi dalam study ini adalah pandangan seseorang terhadap suatu objek yang dipengaruhi penginderaannya, pengetahuan, pengalamannya, dan kebiasaannya sehingga dapat memberi makna dan sikap. Sementara yang dimaksud dengan kenyamanan tata ruang kampus adalah rasa ketentraman, keamanan dan kelegaan seseorang pada pola letak, aksesibilitas, sirkulasi, iklim, kebersihan dan aroma, kebisingan serta keindahan ruang terbuka, bangunan dan ruang kelas, ruang kerja yang dapat memberikan ruang dan keleluasaan untuk berinteraksi dengan komunitas kampus. Konsepsi study ini kemudian dioperasionalisasi dengan menggunakan skala likert dengan pengukuran ordinal

Adapun pendekatan study adalah menggunakan pendekatan kuantitatif deskriptif dengan objek dalam studi ini adalah mahasiswa, dosen, pejabat struktural kampus dan pegawai di lingkungan kampus UIN SU sejumlah 71 orang. Sementara objek persepsi dari studi adalah kenyamanan tata ruang kampus UIN SU. Penarikan subjek studi ditentukan berdasarkan purposive sampling yaitu pengambilan responden dengan pertimbangan tertentu.

Jenis data studi ini adalah data primer dan data sekunder dengan metode pengumpulan data dengan wawancara dengan menggunakan kuesioner, Dokumentasi dan data sekunder melalui studi 
pustaka. Analisis data yang digunakan dalam penelitian ini adalah teknik analisis data kuantitatif deskriptif dimana kuesioner yang telah diskoring, kemudian hitung jumlah dan reratanya. Setelah itu dianalisa dan diinterpretasikan melalui penyajian tabulasi tunggal dan tabulasi silang (cross-tab).

\section{Pembahasan}

Seperti dijelaskan dalam kerangka teori, persepsi civitas akademik terhadap kenyamanan tata ruang kampus Universitas Islam Negeri Sumatera Utara Medan ( UIN SU Medan) merupakan pandangan seseorang terhadap suatu objek yang dipengaruhi penginderaannya, pengetahuan, pengalamannya, dan kebiasaan civitas akademika. Aspek objek tertentu dalam konteks penelitian adalah aspek-aspek kenyamanan tata ruang kampus UIN SU. Dalam perspektif Sosiologis, komponen-komponen persepsi meliputi pengetahuan, perasaan-perasaan, dan pandangan.

Indikator kenyamanan tata ruang kampus adalah pola letak, aksesibilitas, sirkulasi, iklim, kebersihan dan aroma, kebisingan serta keindahan ruang terbuka, bangunan dan ruang kelas, ruang kerja. Oleh karena itu, variabel persepsi civitas akademik diarahkan pada keenam indikator sebagaimana disebutkan dengan 31 butir pernyataan persepsi. Sejak penelitian ini menggunakan skala likert maka Skala Jawaban per item sebagai berikut:

Tabel 1. Skala Skor jawaban

\begin{tabular}{|l|c|}
\hline \multicolumn{1}{|c|}{ Skala Jawaban } & Nilai Skala \\
\hline Sangat Setuju (SS) & 5 \\
\hline Setuju (S) & 4 \\
\hline Netral (N) & 3 \\
\hline Tidak Setuju (TS) & 2 \\
\hline Sangat Tidak Setuju (STS) & 1 \\
\hline
\end{tabular}

Sedangkan jumlah responden dalam penelitian ini adalah 71, maka diperoleh Skor Kriterium (Nilai Skor x Jumlah Responden) sebagai berikut:

Tabel 2. Nilai total Skor Per item Jawaban

\begin{tabular}{|l|l|}
\hline \multicolumn{1}{|c|}{ Rumus } & \multicolumn{1}{c|}{ Skala } \\
\hline $5 \times 71=355$ & Sangat Setuju \\
\hline $4 \times 71=284$ & Setuju \\
\hline
\end{tabular}




\begin{tabular}{|l|l|}
\hline $3 \times 71=213$ & Netral \\
\hline $2 \times 71=142$ & Tidak Setuju \\
\hline $1 \times 71=71$ & Sangat Tidak Setuju \\
\hline
\end{tabular}

Dari nilai pada tabel di atas diperoleh nilai kontinum sebagai berikut:

Tabel 3. Skala Kontinum dari Skor Jawaban Per item

\begin{tabular}{|c|l|}
\hline Nilai Skor & \multicolumn{1}{|c|}{ Skala } \\
\hline $285-355$ & Sangat Setuju \\
\hline $214-284$ & Setuju \\
\hline $143-213$ & Netral \\
\hline $72-142$ & Tidak Setuju \\
\hline $1-71$ & Sangat Tidak Setuju \\
\hline
\end{tabular}

Selanjutnya, Persentase skoring peritem indikator jawaban responden akan dipergunakan untuk menganalisa persentase per item jawaban dalam group indikator. Penghitungan persentase jawaban responden dengan rumus

$$
\begin{aligned}
& \mathrm{p}=\mathrm{f} / \mathrm{n} \times 100 \\
& \mathrm{p} \quad=\text { Presentase } \\
& \mathrm{f} \quad=\text { Frekuensi skala jawaban dari setiap jawaban butir pertanyaan dalam angket } \\
& \mathrm{n} \quad=\text { Jumlah total skor skala per item indikator } \\
& 100 \quad=\text { Bilangan tetap }
\end{aligned}
$$

Nilai presentase skoring jawaban responden ini diinterpretasikan bahwa persepsi subjek penelitian pada kenyamanan tata ruang kampus mulai dari sangat positif hingga sangat negatif. Sementara untuk jawaban seluruh indikator, maka akan diakumulasikan skor jawaban seluruh indikator dibagi dengan total skor ideal untuk seluruh indikator.

Sementara menghitung presentase untuk mendapat interpretasi persepsi sangat positif hingga sangat negatif hasil komputasi skor total jawaban dikalikan 100 persen. Maka baik kriteria interpretasi persentase skor per item atau total jawaban indikator akan menggunakan kriteria persentase sebagai berikut: 
Angka 0\%-20\%= Sangat Negatif

Angka 21\%- $40 \% \quad=$ Negatif

Angka $41 \%-60 \%=$ Netral

Angka 61\%-80\% = Positif

Angka $81 \%-100 \%=$ Sangat Positif

Dari Penelitian lapangan, pengumpulan data sekunder dan analisa data yang dilakukan di dapatkan hasil sebagai berikut:

\subsection{Subjek Penelitian}

Subjek penelitian dapat diihat pada tabel di bawah ini

Tabel 4. Kategori latar Belakang Responden Penelitian

\begin{tabular}{|l|l|c|c|}
\hline No & \multicolumn{1}{|c|}{ Latar Belakang } & Frekuensi & Persentase (\%) \\
\hline 1 & Pegawai & 13 & 18,3 \\
\hline 2 & Dosen Biasa & 12 & 16,9 \\
\hline 3 & Pejabat Struktural & 11 & 15,5 \\
\hline 4 & Mahasiswa & 35 & 49,3 \\
\hline & Total & 71 & 100 \\
\hline
\end{tabular}

Sumber: Hasil Penelitian 2017

\subsection{Persepsi Civitas Akademik}

Persepsi civitas akademik terhadap kebijakan tata ruang kampus merupakan pandangan dan perasaan terhadap berdasarkan pengetahuan dan pengalaman insan akademis UIN SU Medan tentang kebijakan UIN SU berkaitan dengan tata ruang. Berdasarkan data hasil penelitian di peroleh hasil persepsi subjek penelitian sebagai berikut

Terkait persepsi civitas akademik terhadap adanya kebijakan tata ruang kampus adalah bahwa 32,4\% civitas akademik menyatakan netral pada ketersediaan kebijakan tata ruang UIN SU. Persepsi netral menunjukkan bahwa kebijakan sepertinya tersedia namun tidak diketahui secara pasti oleh subjek penelitian. Sementara yang menyatakan sangat setuju adanya kebijakan tata ruang kampus sejumlah $14,3 \%$ dan yang setuju sejumlah 30,9\%. Namun demikian ada 19,7 persen subjek yang menyatakan tidak setuju bahwa UIN SU memiliki kebijakan tata ruang kampus, bahkan ada yang menyatakan sangat tidak setuju walau sangat kecil sejumlah 2,8\%. 
Data ini menginterpretasikan bahwa pengetahuan civitas akademik pada ada atau tidak adanya kebijakan tata ruang kampus masih minim. Ini juga menyiratkan bahwa persoalan tata ruang kampus tidak dibicarakan secara meluas, sehingga civitas akademik secara keseluruhan tidak memahami benar apakah UIN SU memiliki blue print kebijakan tata ruang kampus. Dalam perspektif sosiologi, penting untuk mendiskusikan pada masyarakat atau komunitas atas kebijakan atau hal-hal yang bersentuhan atau menyangkut kehidupan mereka.

Dengan demikian proses penghargaan akan terjadi dan membuahkan partisipatif aktif dari public dalam melaksanakan dan menjaga kebijakan yang ada. Sementara pada sisi Islam, setiap hal yang tidak jelas atau dapat menjadi perdebatan penting untuk di-tabayyun kan sehingga tidak terjadi kesalahan persepsi. Ini termasuk pada informasi terkait kebijakan tata ruang kampus. Tata ruang dalam Islam menjadi sangat penting sebagaimana disebutkan dalam Alquran Surat Alfurqon 48-49 dan juga Q.S. AL-Hajj ayat 45

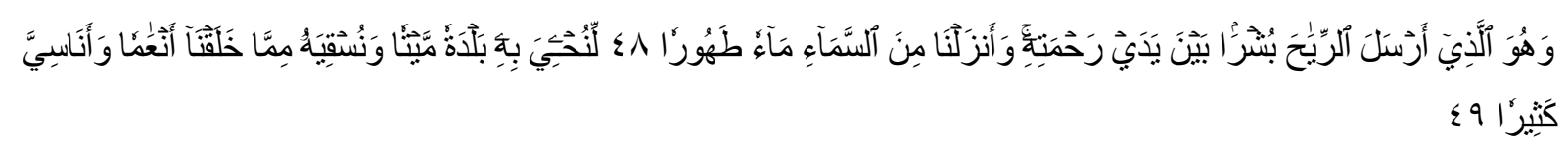

48. Dialah yang meniupkan angin (sebagai) pembawa kabar gembira dekat sebelum kedatangan rahmat-nya (hujan); dan Kami turunkan dari langit air yang amat bersih

49. agar Kami menghidupkan dengan air itu negeri (tanah) yang mati, dan agar Kami memberi minum dengan air itu sebagian besar dari makhluk Kami, binatang-binatang ternak dan manusia yang banyak (Q.S. Alfurqon: 48-49)

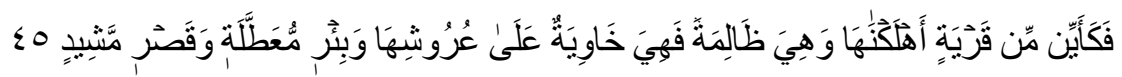

45. Berapalah banyaknya kota yang Kami telah membinasakannya, yang penduduknya dalam keadaan zalim, maka (tembok-tembok) kota itu roboh menutupi atap-atapnya dan (berapa banyak pula) sumur yang telah ditinggalkan dan istana yang tinggi (Q.S. Al-Haj):45)

Surat Alfurqon menyiratkan bahwa manusia haruslah manata ruangnya untuk kemanfaatan semua umat manusia dengan memperhatikan lingkungan dan dengan prinsip partisipasi. Sementara Q.S. Al-Hajj menunjukkan bahwa orang-orang yang tidak memperhatikan aspek pembangunan berwawasan lingkungan akan mendapatkan azabnya. Untuk itu penting sekali mensosialisasikan kebijakan tata ruang kampus pada tingkat fakultas dan civitas akademik sehingga semua memiliki persepsi yang sama bagaimana UIN SU akan dikembangkan dan harus dijaga. 
Sikap pada sosialisasi kebijakan tata ruang kampus menunjukkan bahwa 42,3\% civitas akademik setuju bahwa kebijakan tata ruang kampus sudah disosialisasikan minimal pada tingkat pimpinan fakultas. Ini diperkuat juga oleh civitas akademik yang sangat setuju bahwa kebijakan telah disosialisasikan yakni sejumlah 11,3\%. Namun demikian masih ada yang tidak cukup kuat berpersepsi adanya sosialisasi yakni responden yang menyatakan netral sejumlah 30,9\%, dan bahkan 14,3\% menyatakan tidak setuju dan sangat tidak setuju (1,3\%) akan adanya sosialisasi kebijakan tata ruang kampus pada civitas akademik.

Civitas akademik yang sangat setuju menjelaskan, rencana pembangunan dan pengembangan kampus selalu dibicarakan dan menjadi topik pembahasan rapat periodik pimpinan kampus UIN SU. Dengan demikian kebijakan penggunaan tata ruang kampus secara periodik terus diinformasikan oleh pimpinan UIN SU pada level fakultas dan unit. Di level fakultas dan unit kemudian diharapkan untuk meneruskan pada civitas akademik di tingkat fakultas.

Dengan demikian semua civitas akademik UIN SU merasa memiliki bagaimana kampus akan dikembangkan ke depan dalam tata ruangnya. Namun terlihat memang dari item pertanyaan awal dengan pertanyaan kedua, ada kesenjangan antara persepsi pada sosialisasi kebijakan dengan pengetahuan akan adanya kebijakan. Kesenjangan ini dapat terjadi karena sosialisasi kebijakan tata ruang kampus tidak begitu intensif dilakukan ditingkat fakultas ataupun unit kerja.

Kenyamanan keluar masuk kampus merupakan satu ukuran bagi civitas akademik atau tamu kampus dalam mengukur penataan yang nyaman dan tidak memberikan kesan psikologis semrawut. Sirkulasi keluar masuk kampus UIN SU menurut 38\% civitas akademik sudah mudah dan lancar, namun ada 33,8 \% civitas akademik lainya yang menyatakan tidak setuju bahwa sirkulasi akses kampus UIN SU sangat mudah dan lancar.

Bahkan ada 9,9\% yang menyatakan sangat tidak setuju. Responden yang merespon negatif pada akses keluar masuk kampus menyatakan ada kebingungan jalur yang benar untuk masuk khususnya mobil, perubahan jalur satu arah, sempitnya jalan keluar masuk, hingga jalur keluar sepeda motor dan pejalan kaki yang sama. Jalur masuk sesampai pintu gerbang juga terpecah membingungkan. Situasi itu diperparah dengan angkutan umum yang parkir di depan pintu keluar dan masuk kampus. Ini sangat memungkinkan karena memang luas lahan di kampus UIN SU yang sangat kecil dibandingkan Universiats Negeri lainnya di Sumatera Utara, dan pada sisi lain jumlah mahasiswa di UIN SU yang terus bertambah lebih dari 20 ribu mahasiswa. 
Sementara persepsi civitas akademik pada akses infrastruktur bagi penyandang disabilitas tidak begitu baik. Ada 50,7\% civitas akademik yang menyatakan bahwa tidak tersedia akses bagi penyandang disabilitas di fakultas atau kelas di kampus UIN SU. Hanya 16,9 \% yang menyatakan bahwa kampus dan ruang kuliah UIN SU sudah aksesibel untuk penyandang disabilitas dan ada 5,6 $\%$ yang sangat yakin bahwa ruang fakultas dan ruang kuliah sudah dapat dijangkau oleh penyandang disabilitas.

Penyebab utama yang dituturkan oleh civitas akademik mengapa kampus belum aksesibel bagi penyandang disabilitas karena tidak ada disain bangunan di kampus UIN SU yang dilengkapi tangga landai yang dapat memudahkan akses bagi civitas akademik yang mengalami tuna daksa. Ruang kuliah, kantor bahkan masjid masih memakai tangga. Demikian pula tidak ada railing masuk ruang kantor atau ruang kuliah yang sangat membantu civitas akademik yang menyandang tuna netra.

Persepsi civitas akademik pada kenyamanan suhu udara di ruang kerja atau ruang kelas menunjukkan ada 30,9\% civitas akademik yang menyatakan ruang kampus sudah nyaman. Ditambah yang sangat setuju bahwa ruang kampus sangat nyaman ada 5,6\%. Namun demikian civitas akademik yang tidak setuju kenyamanan suhu udara dalam ruang mencapai 26,7\% bahkan yang sangat tidak setuju berjumlah $16,9 \%$.

Civitas akademik ini menuturkan bahwa banyak kipas angin yang tidak berfungsi dan rusak. Pada sisi lain pada banyak ruang aksesibilitas pada listrik juga sangat terbatas, dimana saklar banyak yang mati. Sementara alasan unit kerja di luar ruang kuliah menyatakan bahwa pendingin ruangan banyak yang rusak sementara ventilasi ruang kantor untuk mendapatkan udara segar tidak mencukupi. Ini menunjukkan bahwa pada ruang kampus dan ruang unit kerja penting pemeliharaan secara berkala infrastruktur elektronik dan juga pendingin udara baik kipas angina ataupun pendingin ruangan.

Pada sisi lain, pandangan civitas akademik pada ruang terbuka hijau di Kampus UIN SU bahwa yang setuju bahwa ruang terbuka hijau masih tersedia luas di kampus hanya 19,7\%. Sementara yang lain ragu-ragu dan menyatakan netral bahwa ruang terbuka hijau di kampus masih tersedia luas, jumlah pandangan netral adalah 36,6\%. Keraguan sebagian civitas akademik ini dikuatkan oleh 30,9\% civitas akademik lainnya yang menyatakan bahwa ruang terbuka hijau di UIN sudah sangat sedikit. Ini menunjukkan berdasarkan pengalaman dan pengetahuan civitas akademik bahwa ruang terbuka hijau di UIN SU sudah tidak begitu luas dan tersedia lagi.

Sementara itu persepsi Civitas Akademik pada Tata Letak bangunan Kampus UIN SU dapat dilihat bahwa subjek penelitian yang netral bahwa tata letak bangunan kampus UIN SU memberikan 
kenyamanan adalah mayoritas sejumlah 50,7\%. Sementara yang setuju ada berjumlah $28,1 \%$. Namun demikian, ada 19,7 \% yang menyatakan tidak setuju bahwa tata letak bangunan kampus memberikan kenyamanan. Mereka menyatakan antar bangunan kampus saat ini sangat berdekatan sehingga tidak ada ruang terbuka lagi.

Alasan yang lain menyatakan bahwa disain bangunan UIN SU pada umumnya disain kontemporer Barat. Rekomendasi para responden, sebaiknya disain bangunan UIN SU mengadopsi disain bangunan Islam kontemporer. Sebagai kampus universitas Islam, UIN SU penting memberikan praktik baik mengintegrasikan arsitektur bangunan kampus dengan nilai dan prinsip Islam.

Dalam sejarah peradaban Islam, pada abad ke-9, khalifah Abdurrahman III di Andalusia adalah orang pertama yang membangun universitas bernama Universitas Cordoba di mesjid Cordoba. Philip K. Hitti menulis dalam bukunya, The Arabs: A Short History, bahwa banyak mahasiswa dan sarjana muslim dan Kristen yang berdatangan untuk belajar dan menggali ilmu pengetahuan tentang Islam (Philip K. Hitti, 1885).

Dapat dipahami bahwa perkuliahan di lakukan di mesjid pada masa universitas cordoba. Dengan demikian tata ruang belajar dan administrasi juga merupakan konsep mesjid dengan setting belajar secara komunal duduk bersila dan melingkar. Di UIN SU Masjid belum dijadikan sebagai pusat belajar secara utuh. Masjid dijadikan tempat belajar bagi mahasiswa yang mendapat kelas tambahan sementara ruang kelas tidak ada lagi. Namun memang, luas bangunan masjid di UIN SU tidak memungkinkan menampung banyak mahasiswa untuk belajar dan pada saat bersamaan dipergunakan untuk ritual ibadah.

Dalam konsep arsitekture Islam, pada dasarnya dikenal konsep integrasi antara aspek sosiologis, budaya dan aspek lingkungan seperti yang disarankan oleh para objek studi ini. Pada aspek lingkungan, Islam mengajarkan tentang sumber daya alam yang diberikan Allah kepada manusia. Dengan demikian struktur bangunan didisain untuk menerima secara maksimum secara bebas dari pemberian Allah SWT tersebut baik dari sinar matahari, angin dan siang hari. Dalam disain arsitektur Islam. Ruang di lantai atas dipergunakan untuk ruang yang lebih hangat sementara ruang di lantai bawah dipergunakan untuk menghindari panas.

Dalam disain arsitek Islam, yang sebenarnya sebagian diadopsi oleh pola tata ruang Melayu, udara dingin yang sejuk dikumpulkan oleh penangkap angin, disebut sebagai Malqaf, untuk 
Persepsi Civitas Akademik Pada Kenyamanan Tata Ruang Kampus UINSU Medan

(Pendekatan Sosiologi Agama dan Transdisiplin Keilmuan)

menyuplai ruangan dalam dengan udara segar, sehingga ruangan bangunan menggunakan ventilasi natural. Ini dikatakan oleh M. Ala Mandour (2012:103)

"The cool breeze wind is collected by the Malqaf (wind catcher/wind tower) to supply the inner rooms with fresh air ventilation. This element is usually repeated in Islamic architecture and was also constructed in Khalil Basha's house, which was used to create natural ventilation in building, and to achieve thermal comfort inside the house, it traps the cool air and channel it down into the interior of the building".

Menurut Hakim (1984) kehadiran Allah dalam arsitekture Islam disimbolisasi melalui munculnya cahaya. Pengintegrasiannya dalam konsep arsitekture bangunan kemudian adalah memaksimumkan penggunaan sinar matahari selama siang hari yang ditandai dengan jendela yang besar dan halaman yang luas. Dalam arsitek budaya melayu, halaman yang luas juga merupakan kebiasaan yang ada dalam membangun rumah atau tempat pertemuan warga. Dalam sejarah Islam konsep halaman rumah telah dipergunakan oleh region Iran di timur dan Atlantik di Arab.

Pada sisi sosiologis, menurut Chermayeff \& Alexander (1966) bangunan didisain menurut privasi ke publik; privat-individu, privat-keluarga, privat-kelompok, public kelompok dan public semikota, atau disebut juga dengan urban-semi public. Maka konsep tata ruang dan bangunan universitas ada pada golongan urban-semi public dan group public atau bahkan sudah masuk pada urban public.

Dengan demikian bangunan universitas harus memperhatikan kebutuhan sosiologis masyarakat semi urban atau bahkan masyarakat urban yang sudah masuk pada individualistis namun pada satu titik dapat menjadi crowd atau menjadi komunal. Sementara pada konsep Islam bangunan dititik beratkan pada privasi individu berhubungan dengan Allah, hubungan dengan keluarga, hubungan dengan tetangga dan hubungan dengan masyarakat lebih luas. Dengan demikian keberadaan halaman universitas harus dapat merepresentasikan esensi pemenuhan kebutuhan antara zabir dan bathin dari penghuni universitas tersebut. Abu Gazzeh (1996) menyatakan integrasi dimensi arsitek, sosial, psikologi merupakan dasar dalam konstruksi bangunan Islam.

"The architectural, social, and psycological dimension of privacy are fundamental to the daily life of a muslim. To control privacy in the built environment, architectural, and behavioral variables must operate in tandem in order to satisfy the psychological needs of its residents."

Karena itu pendekatan sistematik yang mengintegrasikan antara kebijakan, nilai budaya Islam, arsitektural dan prilaku sosial penting dilakukan dalam pengelolaan tata ruang UIN SU. Nilai Islam yang sangat menghargai sumber daya alam, diselaraskan dengan konsep ruang yang memberikan 
kesempatan hubungan antar kelompok dan individu kampus dalam tataran akademis dan nilai Islam. Konsep ini harus diletakkan dalam kebijakan kampus dan dintegrasikan dalam budaya kampus sehingga terbentuk menjadi budaya Insan akademisnya.

\section{Kesimpulan}

Berdasarkan temuan studi persepsi civitas akademik terhadap kenyamanan tata ruang kampus UIN SU Medan, didapatkan bahwa:

1. Persepsi civitas akademik pada kebijakan tata ruang kampus menunjukkan bahwa rerata merupakan persepsi positif dalam interpretasi bahwa kebijakan sudah ada, dan sudah disosialisasikan walau terbatas,

2. Persepsi civitas akademik terkait pada Kenyaman Sirkulasi Akses Kampus UIN SU Medan menunjukkan persepsi yang netral dalam artian umumnya civitas akademik pada satu sisi berpersepsi bahwa akses sudah ada namun tidak cukup baik untuk kelancaran, kemudahan, penerangan maupun keramahan akses bagi penyandang disabilitas

3. Persepsi civitas akademik pada kenyamanan ruang taman adalah netral. Ini disebabkan bahwa taman kampus tidak banyak lagi yang dapat dipergunakan untuk proses interaksi social antar civitas akademik. Sementara ruang unit kerja juga didisain cenderung tidak memiliki ruang social.

4. Persepsi civitas akademik pada kenyamanan iklim kampus menunjukkan pada persepsi netral yang mengartikan akses sirkulasi udara maupun pengaturan suhu udara di kampus maupun ruang kerja tidak buruk namun juga tidak begitu baik

5. Persepsi civitas akademik pada tata letak bangunan kampus menunjukkan bahwa umumnya civitas akademik berpersepsi positif yang mengartikan bahwa tata letak bangunan di kampus II secara relatif memberikan kenyamanan. Namun demikian dalam pembangunan infrastruktur belum banyak mengintegrasikan arsitektur dalam konsep Islam.

Dari analisa data yang disajikan termasuk masukan dari civitas akademik, maka studi ini memberikan rekomendasi: 
1. Perlu dilakukan penelitian lanjutan rekomendasi disain kampus yang menunjang kinerja civitas akademik dan memberikan kemudahan dalam akses beribadah serta mengintegrasikan arsitektur kontemporer Islam dan budaya lokal

2. Infrastruktur kampus khususnya bangunan ruang dan kantor unit kerja perlu untuk dilakukan renovasi guna memberikan keramahan akses fasilitas pada penyandang disabilitas

3. UIN SU dapat menginisiasi sistem IPAL terintegrasi untuk melakukan pengelolaan kebersihan limbah secara terukur dan terpadu.

4. UIN SU perlu membuat regulasi berkaitan dengan sirkulasi dan kebisingan kenderaaan dalam lingkungan kampus.

\section{Daftar Pustaka}

Ahmad Musthafa Al-Maraghi, 1993, Terjemah Tafsir Al-Maraghi 21, Semarang: PT. Karya Toha Putra,

Abidin, Zainal Wajih.,(1997) Kebutuhan Muslim, Gema Insani Press, Jakarta

Ahmad. 1997. Evaluasi Penggunaan Lahan Daerah Perbukitan dan Pengarubnya terhadap Masalah Lingkungan Fisik di Kotamadya Ambon. Tesis. Yogyakarta: Program Pascasarjana UGM.

Arikunto, Suharsimi. 1998. Prosedur Penelitian Studi Pendidikan Praktek. Edisi IV . Jakarta

Bimo Walgito. 1989. Pengantar Psikologi Umum. Yogyakarta. Andi Offset.

Bergmann,Mathias, 2009, A Collection of Methods and Examples for Integration in Transdiciplinary Research (19-21 November, Berne).

Carr, S., M. Francis, L.G. Rivlim, \& A.M. Stone. 1992. Public Space. Cambridge: Cambridge University Press.

Drs. Dyayadi, 2008, Tata Kota Menurut Islam, Pustaka Al-Kautsar, Jakarta

Erlangga Hasan, Mohammad. 2009 . Skripsi ; Hubungan Tata Ruang Antara Persepsi Tentang Tata Ruang Kerja Dengan Kepuasan Kerja Karyawan di Instansi Pemkot Kediri. Universitas Negeri Malang.

George Ritzer - Douglas J. Goodman, 2007, Teori Sosiologi Modern, Jakarta, Kencana Prenada Media Group.

Groat, Linda \& David Wang. 2002. Architectural Research Methods. New York: John Wiley \& Sons

Hariyani, 2006, Pengaruh Kampus Terhadap Ruang Urban: Kasus Ruang Urban Pada Akses Masuk Kampus Universitas Gajah Mada. Tesis. Yogyakarta: Pasca Sarjana UGM 
Hitti, Philip K dalam Ismail Faisal, 2016, Paradigma Kebudayaan Islam, Studi Kritis Analisa Historis, Yogyakarta, Penerbit Ombak.

Jayadinata, Johara T. 1999. Tata Guna Tanah dalam Perencanaan Pedesaan Perkotaan dan Wilayah. Bandung: ITB Bandung.

Krier, Rob. 1979. Typological and Morphological Elements of The Concept of Urban Space. New York: Rizzoli.

M Alaa. Mandour, 2012, Contemporary Architecture of Islamic Societies , UIN-Maliki Press, Malang

Nasution, 1988. Metodologi Penelitian Kualitatif. Bandung : PT. Remaja Rosdakarya.

Nurmandi, Achmad. 1999. Manajemen Perkotaan. Yogyakarta: Lingkaran Bangsa

Rossi, Aldo, 1982. Architecture Of the City, London-England. The MIT Press.

Sarwono, Sarlito Wirawan, 1992, Psikologi Lingkungan, Grasindo, Jakarta

Setiawan, Muhammad Aris, 2015, Konsep kota layak huni (livable city) dalam al-Qur'an. Undergraduate (S1) thesis, UIN Walisongo. - http://eprints.walisongo.ac.id/4451/

Sugiyono. 2015. Metode Penelitian Pendidikan Pendekatan Kuantitatif, Kualitatif dan R\&D. Bandung. Alfabeta.

Sugiyono. 2008. Metode Penelitian Kuantitatif, Kualitatif, R \&D. Bandung: Alfabeta

Kementrian Agama RI, Al-Qur'an dan Tafsirnya Jilid X Juz 28-29-30, 2010, Jakarta: Lentera Abadi, 